\title{
Optimisation of Inner Diameter to Outer Diameter Ratio of Axial Flux Permanent Magnet Generator
}

\author{
A. H. Saifee ${ }^{1}$, Arvind Mittal ${ }^{2}$ \\ I'Vice Principal, All Saints' College of Technology, Bhopal, India) \\ ${ }^{2}$ (Associate Professor, Maulana Azad National Institute of Technology, Bhopal, India)
}

\begin{abstract}
This paper presents design of axial flux permanent magnet generator using torus construction of stator with plastic material. To maximise the efficiency of the generator, the losses are to be minimized in proposed $\mathrm{N}$-S Arrangement iron loss is absent and only copper losses are present. To minimise the copper loss for a given rating, the per phase stator resistance is to be minimised. The relation between Internal Diameter (ID) to Outer Diameter (OD) Ratio and the per phase resistance has been developed and optimal value is worked out. Also the designs were prepared for various ID to OD ratios to verify the optimal results.
\end{abstract}

Keywords: Axial flux machine, Torus design, Plastic material stator, ID to OD ratio, Optimisation, $R_{\text {ph } 75}$

\section{Introduction}

In last few decades researchers and scholars are working towards more and more energy efficient machines and non conventional energy resources because of fast diminishing of our conventional resources of energy.

Electrical machines has three components of losses viz copper losses due to current, iron losses due to magnetic material and friction losses due to rotation. In last one decade the efforts towards energy efficient machine has promoted the use of Axial Flux Machine. Popularity of axial flux permanent magnet generators are mainly of N-S, S-N configuration ${ }^{[1]}$ which does not require iron in stator and plastic material is used which gives an advantage of no iron loss in the stator and low weight construction. Further plastic construction motivates for slot less design of stator.

Among Renewable energy sources, wind energy system is most popular as wind is available throughout the year, may be in different quantum and speed. Wind mill has a typical application where it is low speed and further speed and power is not constant but depends upon wind velocity and pressure. Wind mill generator design should be such that it does not obstruct wind flow. Axial Flux generators are most suited for such application because of low weight stator and low inertia.

\section{Principle Of Operation}

In Axial Flux Permanent Magnet Generator (AFPMG), the stator is in the form of disc housing winding and rotor is a permanent magnet along with end plates. Stator and Rotor are separated by an Air Gap which is measured axially. The magnetic flux in the air gap passes axially and hence it is termed as Axial Flux Generator. The general arrangement of AFPMG is shown in Fig 1.

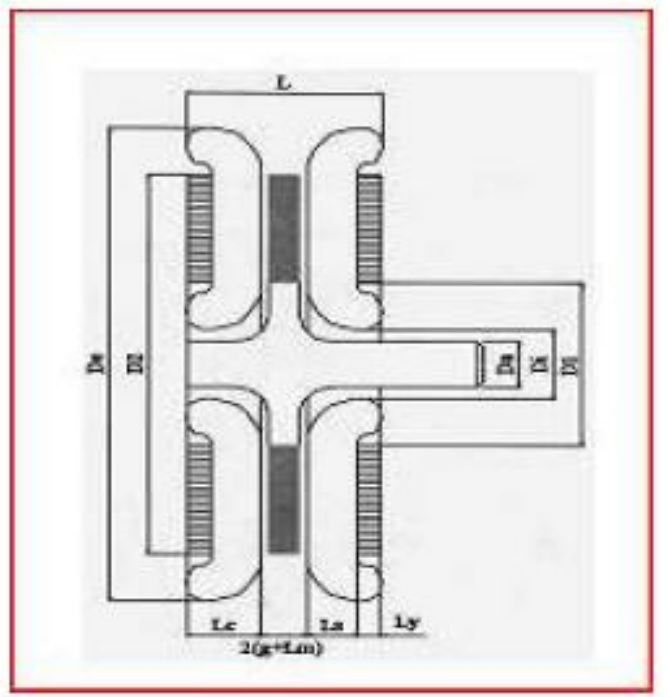

Fig 1 - General Arrangement of AFPMG 
The sizing equation is derived from the basic equation $(\mathrm{e}=\mathrm{Blv})$ is given as follows:

$$
\mathrm{P}_{\text {out }}=\frac{\Pi^{2}}{8} \times \mathrm{B}_{\mathrm{av}} \times \mathrm{ac} \times\left(\mathrm{D}_{\text {outer }}\right)^{3} \times\left(1-\mathrm{k}^{2}\right) \times(1+\mathrm{k}) \times \mathrm{N}_{\mathrm{s}} \times \cos (\varphi) \times \eta \times \mathrm{N}_{\text {stage }}
$$

Where,

$\mathrm{P}_{\text {out }}=$ Power output

$\mathrm{B}_{\mathrm{av}}=$ Air gap Flux Density

$\mathrm{ac}=$ Ampere Conductor $/$ Stator Periphery

$\mathrm{D}_{\text {outer }}=$ Outer diameter of Stator.

$D_{\text {inner }}=$ Inner diameter of Stator.

$\mathrm{k}=\mathrm{D}_{\text {inner }} / \mathrm{D}_{\text {outer }}$

Ns = Synchronous Speed in RPS

$\operatorname{Cos}(\varphi)=$ Power Factor

$\eta=$ Efficiency

$\mathrm{N}_{\text {stage }}=$ Number of Stages.

\section{Construction}

Author has already established ${ }^{[1]}$ that among various combinations of AFPMG the best option is N-S \& S-N combination (stator sandwiched between two rotors) where; in stator plastic materials can be used. Further non slotted design ${ }^{[5]}$ leads to low noise machine. Construction with multiple discs of stator and rotor are also known as multistage AFPMG arrangements which are shown in Fig. 2 as below.

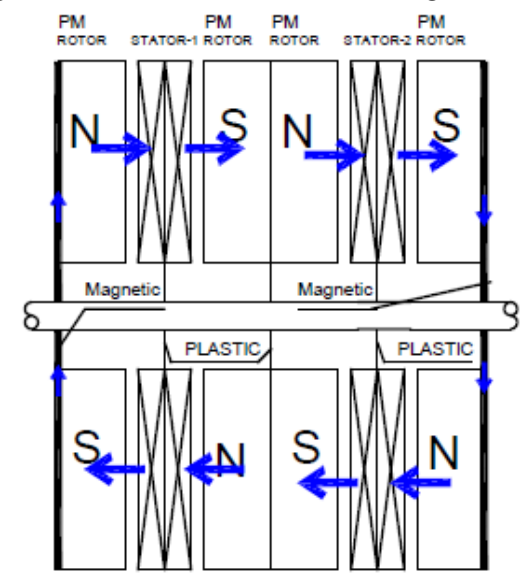

Fig 2 - Multistage AFPMG arrangement

The flux through rotor intermediate stages neither pass radial nor tangentially hence the rotor disc of intermediate stages also can be of non magnetic and hence plastic and only outer disc of rotor will be magnetic. Moreover in case of proposed arrangement of AFPMG, mainly there is only one component of loss and that is copper loss due to stator winding. Stator winding's active part is radial from $D_{\text {inner }}$ to $D_{\text {outer }}$ and $D_{\text {outer }}$ to $D_{\text {inner. }}$ At $D_{\text {outer }}$ number of layers will be less and at $D_{\text {inner }}$ it will be much more which will result in more axial thickness of stator at $D_{\text {inner }}$ and thinner at $D_{\text {outer. }}$. Stator winding resistance is dependent on $D_{\text {outer }}$ and $D_{\text {inner }}$.

\section{Effect of ID to OD ratio}

From Equation 1, it is clear that Outer Diameter $\left(\mathrm{D}_{\text {outer }}\right)$ of the AFPMG will depend upon factor k i.e. ratio of Inside Diameter (ID) to Outside Diameter (OD) for a given specification of machine. Further since in AFPMG with stator sandwiched between Rotors with N-S and S-N arrangement, iron losses are absent and only copper losses exists. The copper loss is mainly because of stator winding resistance. The efficiency of generator is given by:

$\eta=$ output/(output + losses)

Since output is fixed, hence for maximum efficiency, it is the losses which is to be minimised.

$$
\frac{\partial(\text { losses })}{\partial \mathrm{k}}=0
$$


To maximize the efficiency it is necessary to minimise the losses and losses comprise of only copper losses as the Iron losses are not present. Copper loss is given as:

$$
\begin{aligned}
& \text { losses }=\mathrm{I}_{\mathrm{ph}}^{2} \times \mathrm{R}_{\mathrm{ph} 75} \\
& \frac{\partial(\text { losses })}{\partial \mathrm{k}}=\frac{\partial\left(\mathrm{I}_{\mathrm{ph}}^{2} * \mathrm{R}_{\mathrm{ph} 75)}\right.}{\partial \mathrm{k}}=\mathrm{I}_{\mathrm{ph}}^{2} \times \frac{\partial \mathrm{R}_{\mathrm{ph} 75}}{\partial \mathrm{k}} \\
& \mathrm{R}_{\mathrm{ph} 75}=\frac{1.732 \times 10^{-8} \times \mathrm{L}_{\mathrm{mt}} \times \mathrm{N}_{\mathrm{ph}} \times 1.3}{\text { Acond }} \\
& \text { Where, } \\
& \mathrm{L}_{\mathrm{mt}}=\text { Length of mean turn }(\mathrm{m}) \\
& \mathrm{N}_{\mathrm{ph}}=\text { Number of turns } / \mathrm{phase} \\
& \mathrm{A}_{\text {cond }}=\text { Area of Conductor }\left(\mathrm{m}^{2}\right) \\
& \mathrm{R}_{\mathrm{ph} 75}=\text { Resistance per Phase at } 75^{\circ} \mathrm{C}(\mathrm{Ohms})
\end{aligned}
$$

The length of mean turn is given by:

$\mathrm{L}_{\mathrm{mt}}=\mathrm{D}_{\text {outer }}-\mathrm{D}_{\text {inner }}+\frac{\pi}{\mathrm{P}} \times\left(\mathrm{D}_{\text {outer }}+\mathrm{D}_{\text {inner }}\right)$

Where, $\mathrm{P}=$ Number of poles

The number of turns per phase is given by:

$\mathrm{N}_{\mathrm{ph}}=\frac{\mathrm{ac} \times \pi \times\left(\mathrm{D}_{\text {outer }}+\mathrm{D}_{\text {inner }}\right)}{2 \times \mathrm{I}_{\mathrm{ph}} \times 2 \times \text { Phase }}$

Where,

$\mathrm{ac}=$ Ampere Conductor $/ \mathrm{m}$

$\mathrm{I}_{\mathrm{ph}}=$ Phase current (Amps)

Phase $=$ Number of Phases

From Equation 1, we get

$\mathrm{D}_{\text {outer }}=\sqrt[3]{\frac{\alpha}{\left(1-\mathrm{k}^{2}\right) \times(1+\mathrm{k})}}$

$\alpha=\frac{\mathrm{P}}{1.25 \times \mathrm{B}_{\mathrm{av}} \times \mathrm{ac} \times \mathrm{N}_{\mathrm{s}} \times \eta \times \cos (\varphi) \times \mathrm{N}_{\text {stage }}}$

Substituting the value of $\mathrm{L}_{\mathrm{m}}, \mathrm{D}_{\text {outer }}$ and $\mathrm{D}_{\text {inner }}$ in Equation 4, we get;

$\mathrm{R}_{\mathrm{ph} 75}=1.732 \times 10^{-8} \times \mathrm{ac} \times \Pi \times \sqrt[\frac{2}{3}]{\alpha} \times \frac{1.3}{12 \times \mathrm{A}_{\text {cond }} \times \mathrm{I}_{\mathrm{ph}}} \times \sqrt[3]{\frac{1}{(1-\mathrm{k})\left(1-\mathrm{k}^{2}\right)}} \times\left[\mathrm{k} \times\left(\frac{\Pi}{\mathrm{P}}-1\right)+\frac{\Pi}{\mathrm{P}}+1\right]$

The above equation clearly indicates that $\mathrm{R}_{\mathrm{ph} 75}$ depends on the variable ' $\mathrm{k}$ ' which is the ratio of Inner Diameter to Outer Diameter (ID/OD) of stator.

\section{Optimization Of ID To OD Ratio}

The optimization problem is formulated to minimize the objective function $\mathrm{R}_{\mathrm{ph} 75}$ such that the variable ' $\mathrm{k}$ ' along with $\mathrm{B}_{\mathrm{av}}$ and ac satisfies the constraints of Efficiency, Temperature rise and Power Factor.

Since objective function is a well defined function in ' $\mathrm{k}$ ' in the form of linear function so in order to minimise the well known method of differentiating the objective function $\mathrm{R}_{\mathrm{ph75}}$ with respect to ' $\mathrm{k}$ ' and equating it to zero is adopted.

Rewriting equation 9 with introduction of a constant $\beta$,

$$
\begin{aligned}
& \mathrm{R}_{\mathrm{ph} 75}=\beta \times \sqrt[3]{\frac{1}{(1-\mathrm{k}) \times\left(1-\mathrm{k}^{2}\right)}} \times\left[\mathrm{k} \times\left(\frac{\pi}{\mathrm{P}}-1\right)+\frac{\pi}{\mathrm{P}}+1\right] \\
& \beta=\frac{1.732 \times 10^{-8} \times \mathrm{ac} \times \pi \times \sqrt[2 / 3]{\mathrm{a}} \times 1.3}{12 \times \mathrm{A}_{\text {cond }} \times \mathrm{I}_{\mathrm{ph}}}
\end{aligned}
$$

Differentiating $\mathrm{R}_{\mathrm{ph} 75}$ with respect to $\mathrm{k}$ and equating it to zero, we get 
$\left(\frac{4 \times \Pi}{3 \times \mathrm{P}}+\frac{2}{3}\right) \times \mathrm{k}^{2}-\frac{4 \times \mathrm{k}}{3}-\frac{4 \times \Pi}{3 \times \mathrm{P}}+\frac{2}{3}=0$

11

From Equation 11, it is clear that value of for optimum efficiency is independent of Power, Current, Specific loadings etc and is only dependent on $\mathrm{P}$ i.e. Number of poles.

Considering the Number of poles as 10 , value of $\mathrm{k}$ for maximum efficiency was obtained as 0.23

For verification of the value of ' $\mathrm{k}$ ' as obtained above the designs of $500 \mathrm{~W}-5000 \mathrm{~W}, 5 \mathrm{RPS}, 440 \mathrm{~V}$, 3Phase, $25 \mathrm{~Hz}$ AFPMG were prepared in different stages from $1-6$ stages with various ID / OD ratio varying from 0.1 0.6. Curves are plotted of the efficiency verses K (ratio ID/OD) curves are plotted for stages 1,2 and 6 as shown in Fig: 3 which clearly indicate that maximum efficiency is occurring for ID to OD ratio of 0.23. As seen from Fig: 3, multistage design even though is less efficient but it will make more wind available for higher power generation.

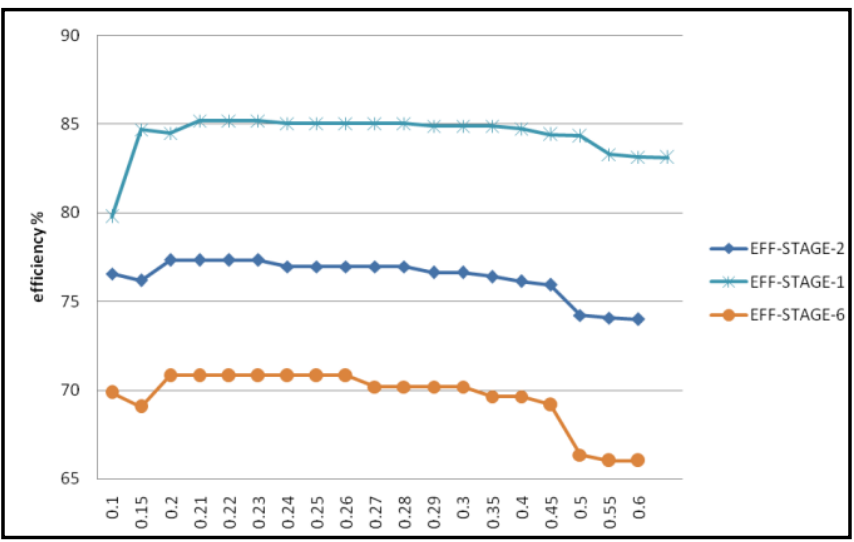

Fig.3: Efficiency v/s K for various stages

The efficiency versus ' $k$ ' for various power ratings ranging from $500 \mathrm{~W}$ to $5000 \mathrm{~W}$ is shown in Fig: 4 . It can be depicted from the curve that maximum efficiency occurs for a value of ' $\mathrm{k}$ ' ranging from 0.21 to 0.23 .

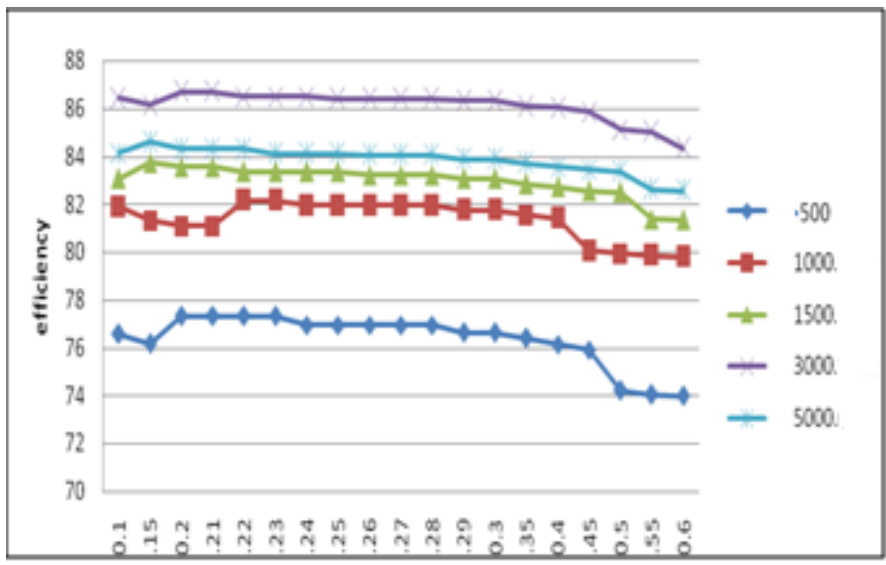

Fig. 4: Efficiency v/s K for various power ratings

This further confirms that the finding of $\mathrm{k}$ for maximum efficiency as 0.23 . Slight variation is because in the design, the OD and ID values are rounded off to the nearest $\mathrm{mm}$, conductor area to available gauges and Number of turns to integer for per coil turn. Higher ID/OD ratio will cause high effective length of coil and overhang and will result in more Copper losses. The low values of ID/OD ratio will obstruct air circulation and will ultimately lead to higher temperature rise. Hence, it is very essential to optimally select the ID/OD ratio.

\section{Conclusion}

An optimal design of energy efficient Axial Flux Permanent Magnet Generator is disused, which is best suited for Wind applications. The stator resistance per phase is minimized to achieve maximum efficiency with varying ID to OD ratio. The optimum value of ' $\mathrm{k}$ ' is independent of power, current, specific loadings and the number of stages. It was observed that the maximum efficiency occurs for a value of ' $\mathrm{k}$ ' equal to 0.23 . By optimally selecting the value of ID to OD ratio the AFPMG is best suited for wind mill operation as it will not 
block air being of lower diameter and weight. Hence low vibration and light shaft. With the discussed benefits the AFPMG is also highly suitable for electric vehicle applications.

\section{References}

[1]. A H Saifee and Dr. Arvind Mittal, "Design Comparison of Radial Flux Permanent Magnet Generator and Axial Flux Permanent Magnet Generator" International Journal of Electrical and Electronics Engineering Research (IJEEER) TRANS STELLAR, ISSN(P): 2250-155X; ISSN(E): 2278-943X, Vol . 4, Issue 3, pp 35-42, Jun 2014(IF:5.96)

[2]. P. Campbell, "Principles of a permanent-magnet axial-field DC Machine", Proc. IEE, Vol. 121, Dec. 1974, pp.1489-1494.

[3]. C. C. Jensen, F. Profumo and T. A. Lipo, "A low loss permanent Magnet brushless DC motor utilizing tape wound amorphous iron", IEEE Transaction on Industry Applications, Vol. 28, No. 3, May/June 1992, pp.646-651.

[4]. T. A. Lipo, S Huang and M. Aydin, "Performance assessment of axial Flux permanent magnet motors for low noise applications", Final Report to ONR, Oct 2000 .

[5]. S. Huang, M. Aydin and T. A. Lipo, "Low noise and smooth torque Permanent magnet propulsion motors: Comparison of nonslotted and Slotted radial and axial flux topologies", IEEE International Aegean Electrical Machine and Power Electronic Conference, Kusadasi-Turkey, 2001, pp.1-8.

[6]. S. Huang, M. Aydin and T. A. Lipo, "TORUS concept machines: preprototyping Design assessment for two major topologies", IEEE Industry Applications Society Annual Meeting, Chicago, 2001.

[7]. M. Aydin, S. Huang and T. A. Lipo, "Design and electromagnetic field Analysis of non-slotted and slotted TORUS type axial flux surface Mounted disc machines", IEEE International Conference on Electrical Machines and Drives, Boston, 2001, pp.645-651.

[8]. S. Huang, J. Luo, F. Leonardi, and T. A. Lipo, "A general approach to Sizing and power density equations for comparison of electrical Machines," IEEE Trans. on Industry Applications, IA-34, No.1, pp.92-97, 1998.

[9]. S. Huang, J. Luo, F. Leonardi and T. A. Lipo, "A comparison of power Density for axial flux machines based on the general purpose sizing Equation”, IEEE Trans. on Energy Conversion, Vol.14, No.2 June 1999, pp.185-192.

[10]. F. Profumo, A. Tenconi, Z. Zhang and A. Cavagnino, "Novel axial flux Interior PM synchronous motor with powdered soft magnetic material”, IEEE Industry Applications Society Annual Meeting, 1998, pp.152-158. 